
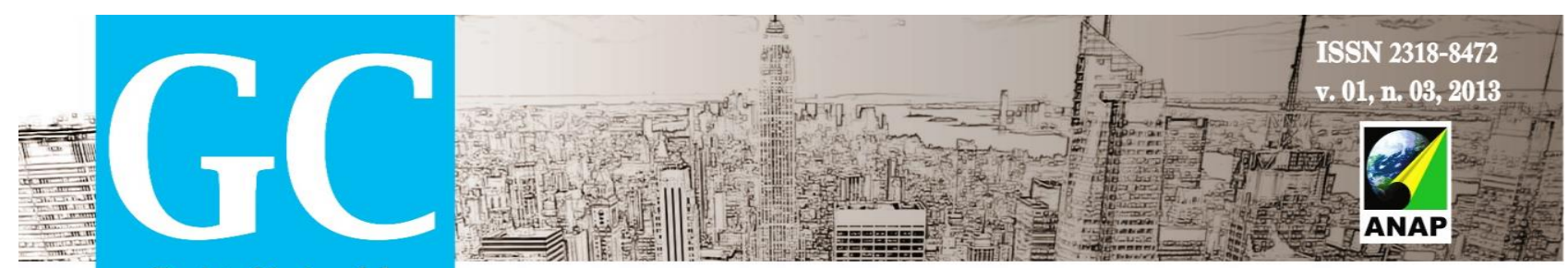

Revista Nacional de

Gerenciamento de Cidades

\title{
O ESPAÇO PÚBLICO URBANO: UMA HISTÓRIA DE LUTAS E DESAFIOS
}

Nilzete Ferreira ${ }^{1}$

Antonio Carlos de Miranda ${ }^{2}$

RESUMO: Analisar o espaço e o meio ambiente é antes de tudo interpretar o que representam, no sentido de estarem impregnados das suas 'múltiplas e variantes determinações'. O espaço vivido é um espaço de produção e reprodução contido em meio às lutas e aos conflitos. $O$ espaço urbano não representa apenas a imagem arquitetônica, mas as imagens da ação, do simbólico e da memória, envolvidas com este espaço. Nesse sentido, o objetivo deste artigo é trazer à tona uma discussão histórica relativa ao conceito de espaço, lembrando que a cidade não é simplesmente um conjunto de edificações, mas construções sociais envolvendo, entre outros aspectos, relações de poder e de conquistas, em que a qualidade de vida da população deve ser um direito à cidadania incluída no planejamento urbano.

Palavras chave: Ambiente. Urbanização. Espaço público.

\footnotetext{
${ }^{1}$ Professora Msa.. - Centro Universitário Augusto Motta- RJ- nilzete16@yahoo.com.br

${ }^{2}$ Professor Dr. - Programa Stricto Sensu da Anhanguera/Educacional- RJ. - miratam@ig.com.br
} 

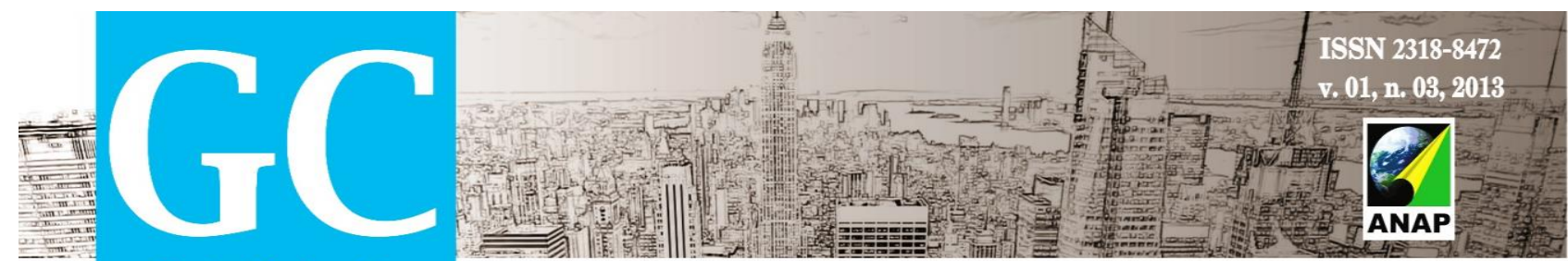

Revista Nacional de

Gerenciamento de Cidades

\section{INTRODUÇÃO}

Na produção do espaço, o ser humano incorpora sua história e coparticipação no ambiente capaz de gerar um elo afetivo. Santos (2007, p.124) lembra que os Direitos inalienáveis do homem incluem entre outros, a moradia e o lazer sendo dever da sociedade e um direito do indivíduo. O serviço público é assim, maquiado como privado onde o grupo social precisa "negociar" os bens de direito como salienta este autor: "a se obterem privadamente; não é um dever social, mas um bem de mercado". O cidadão articula o seu ambiente, ensina e aprende com este, caracterizando uma exploração da consciência antes da prática capaz de refletir em sua vida. É na progressiva modificação de sua habitação e do seu entorno que a história testemunha suas representações.

A rua e a praça se tornam o palco das comemorações e reivindicações do cidadão, em busca de um alerta, seu samba, suas danças é a linguagem onde nesses espaços públicos as classes se misturam. Vale mencionar que a Lei Orgânica da Saúde ํo 8080/90 dispõe a saúde como um direito fundamental do ser humano sendo dever do Estado sua promoção, proteção e recuperação. Para tanto, faz-se necessário entender que dentre os fatores determinantes e condicionantes para a saúde estão o meio ambiente e o lazer mas, antes de tudo é reconhecer o que o ambiente representa, impregnado das 'múltiplas determinações' capaz de buscar a subjetividade na realidade de um grupo social. Neste espaço, o significado de lazer reflete na forma de dispor de um tempo para entretenimento, ou mesmo descanso.

Nesse sentido, para Carlos (2001), 'a paisagem é humana', é a materialização produzida na relação entre as formas e funções em que a cidade surge como produto dessas relações, representada nas construções e no uso do espaço. Portanto, o espaço urbano é palco dessas relações de seus agentes sociais, construindo sua história no enfrentamento de lutas e de conflitos. 

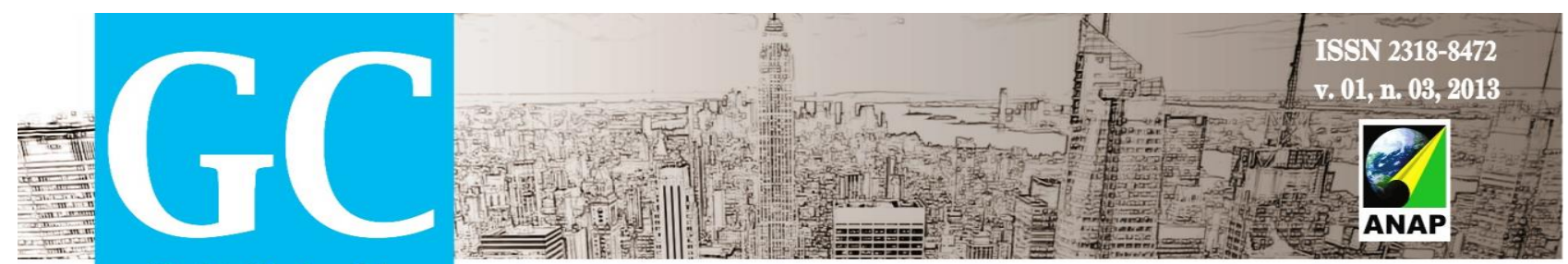

Revista Nacional de

Gerenciamento de Cidades

Levar em conta a trajetória de um grupo social fundamentando na produção/transformação do seu espaço é considerar o diálogo e a escuta inserindo-o neste meio. Por sua vez, Santos (2007, p.155) irá refletir sobre a questão da "ideologia do consumo", impregna o cidadão de mediações e aparências afirmando: "quando se confundem cidadão e consumidor, a educação, a moradia, a saúde, o lazer aparecem como conquistas pessoais e não como direitos sociais".

Atento a essas questões, o objetivo deste artigo é trazer à tona uma discussão histórica relativa ao conceito de espaço, lembrando que a cidade não é simplesmente um conjunto de edificações, mas construções sociais envolvendo, entre outros aspectos, relações de poder, em que a qualidade de vida da população deve ser conquistada, como um direito de cidadania incluída no planejamento urbano.

\section{DESENVOLVIMENTO}

É importante destacar que o conceito de 'paisagem', 'lugar', 'região', 'espaço', entre outros, são discutidos também no pensamento geográfico. A descrição de 'lugar' passou a ser o seu maior destaque, fundamentalmente, através de relatos de viagens e a sistematização deste conhecimento como: a extensão da Terra, dos continentes, as rotas marítimas, entre outros, estabeleceram significativas mudanças nas relações com o meio. Da exploração colonial ao capitalismo, esses conceitos foram se estruturando com temas de interesses político, filosóficos e econômicos, porém, na Teoria da Evolução é que vão ter maior destaque:

Darwin e Lamarck dá um lugar de destaque, em sua explicação, ao papel desempenhado pelas condições ambientais; na evolução das espécies, a adaptação ao meio seria um dos processos fundamentais. (MORAES, 2005, p. 56)

Moraes (2005, p.34-35) cita três possibilidades na concepção de espaço: "categoria do entendimento"; "um atributo dos seres"; ou "um ser específico do real, com características e com uma dinâmica própria". Compreender a relação entre sociedade e natureza estruturou o início da Geografia tradicional com base no positivismo levando a 

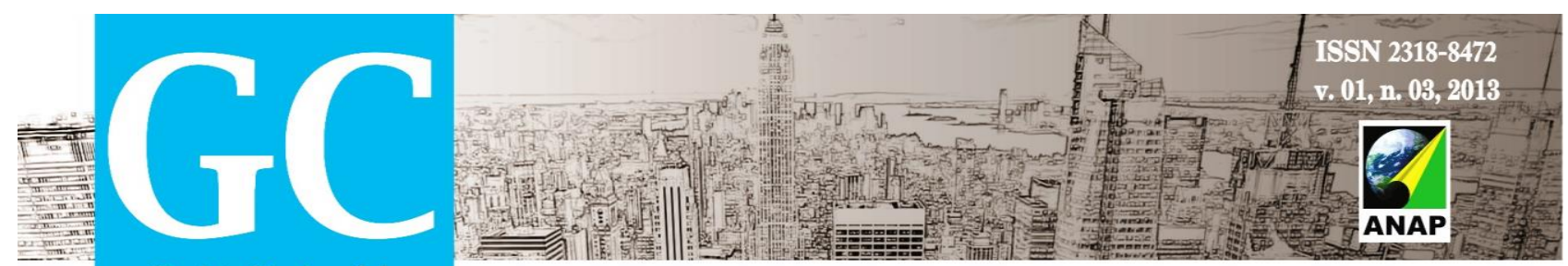

Revista Nacional de

Gerenciamento de Cidades

"descrição, enumeração e classificação dos fatos referentes ao espaço" (MORAES, 2005, p.40).

A discussão acerca do espaço irá permitir uma sistematização do estudo da Geografia na Alemanha no século XIX, com seus principais representantes: Alexandre Von Humbold (1769-1859) e Karl Ritter (1779-1859). Nos pressupostos do primeiro, a contemplação da paisagem através de uma observação sistemática e raciocínio lógico conduziria a explicação de forma generalista; enquanto Ritter buscou a metodologia no estudo da individualidade de cada lugar com a noção antropocêntrica. $O$ ideal de unificação da Alemanha no final do século XIX foi palco para Friedrich Ratzel (1844-1904) legitimar o expansionismo, nesse sentido, na Geografia Humana definindo como objeto de estudo a influência das condições naturais sobre a humanidade, elaborando o conceito de "espaço vital”"3. Os seguidores de Ratzel constituíram, por um lado, a escola determinista condicionando o indivíduo à influência do meio ${ }^{4}$, e, por outro, a escola ambientalista propondo a relação do ser humano com os elementos do meio.

Por sua vez, da ação passiva à reação modeladora de seu espaço, Corrêa aponta a visão de Paul Vidal de La Blache (1845-1918), onde

[...] a natureza foi considerada como fornecedora de possibilidades para que o homem a modificasse; o homem é o principal agente geográfico, nesta visão, La Blache colocou o homem como um ser ativo, que sofre a influência do meio, porém que atua sobre este, transformando-o. Observou que as necessidades humanas são consideradas pela natureza, e que o homem busca as soluções para satisfazê-las nos materiais e nas condições oferecidas pelo meio. (MORAES, 2005b, p.81)

Porém Moraes (2005, p.84) estabelece crítica à Geografia de 'La Blache' por ela não considerar a relação entre os seres humanos. A partir dos pressupostos anteriores,

\footnotetext{
${ }^{3}$ ‘Espaço vital', para Ratzel, constituía a proporção de equilíbrio entre a população de uma sociedade e os recursos disponíveis para suprir suas necessidades.

${ }^{4}$ É importante lembrar que Marx, em 'Teses sobre Feuerbach', discorda de uma visão que coloca o ser humano como produto do meio ou da educação; "efeitos transformadores pelas circunstâncias e pela educação esquece que os seres humanos transformam as circunstâncias e que os próprios educadores precisam ser educados".
} 


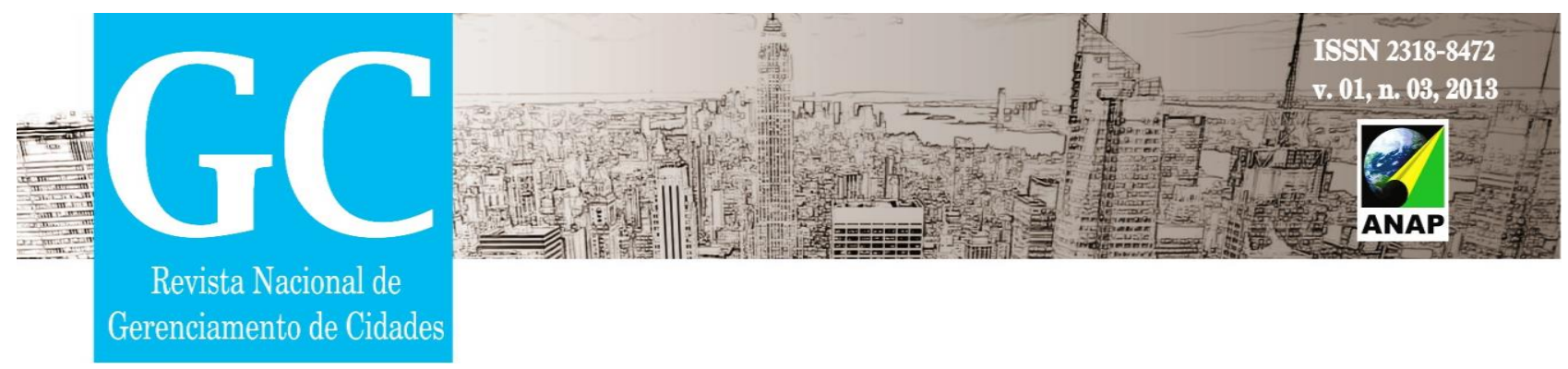

Max Sorre, na década de 1940, aponta para a importância do conceito de habitat como construção humana e suas múltiplas relações entre o homem e o ambiente que o envolve.

Cabe lembrar que a partir da Revolução Industrial com a urbanização crescente o espaço implicava em uma nova dinâmica. Com efeito, Moraes (2005, p.122) descreve a conceituação de Yves Lacoste na diferenciação entre o cidadão com uma visão fragmentada do seu espaço dependendo das suas necessidades e o Estado com uma visão totalizadora. Assim, Lacoste propõe a "visão integrada do espaço, numa perspectiva popular, e socializar este saber".

O espaço passa a ter outras conotações, por exemplo, o conceito de 'região' é desenvolvido por Corrêa (2007, p.42), citando a Lei do desenvolvimento desigual e combinado de Trotsky, ${ }^{5}$ baseada na diferenciação intra e intergrupos em que ocorre pela "enorme distância em termos espaços-temporais". Para este autor, o papel da organização espacial como condição para a reprodução social está sendo mais evidente, quando se consideram as diferentes classes sociais e suas frações em um meio urbano. "É, em grande parte, através da segregação residencial que estas se reproduzem" acrescenta que "a partir do bairro enxerga-se a cidade e o mundo. Um bairro e seu sistema de valores estável possibilitam maior produção do grupo social que ali vive." (CORRÊA, 2007, p.74)

Estabelecer a relação do espaço é conceber o ambiente como objeto do campo de interdisciplinaridade articulado na dinâmica com outras áreas do saber, assim, a questão ambiental é considerada por Leff (2006, p.11) "uma problemática de caráter

\footnotetext{
${ }^{5}$ Alguns esclarecimentos devem ser apresentados sobre a referência acerca da 'Lei' de Leon Trotsky, para isso, acreditamos que o texto, a seguir, de Demier (2003, p.2) nos parece adequado para o seu melhor entendimento. "Entretanto, as burguesias periféricas, surgidas tardiamente na arena histórica, atreladas ao capital estrangeiro e aos grandes proprietários rurais, e extremamente temerosas do proletariado, seriam, segundo Trotsky, incapazes de realizar qualquer tipo de revolução "democrática", o que colocava na ordem do dia para os trabalhadores dos países atrasados a conquista do poder político. Na concepção de Trotsky, portanto, seria o modo combinado como o capitalismo se desenvolvia que designaria o caráter da revolução e os sujeitos sociais revolucionários nos países atrasados. $A$ adição do elemento "combinado" na lei do desenvolvimento desigual de Lênin fez com que Trotsky desse à síntese de suas concepções expressas acima o nome Lei do desenvolvimento desigual e combinado."
} 

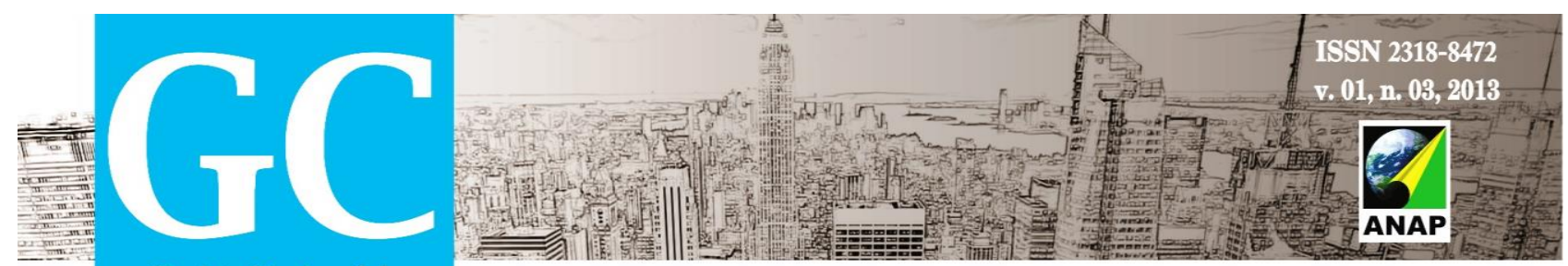

Revista Nacional de

Gerenciamento de Cidades

eminentemente social: esta foi gerada e está atravessada por um conjunto de processos sociais".

Para compreender a relação entre 'espaço' e 'meio ambiente', trazemos à tona o pensamento de Mumford (1965, p.152) quando descreve de forma clara e atual o desenvolvimento da 'aldeia', da 'cidadela' até a caracterização da 'cidade' com sua estrutura física:

[...] a cidade desempenha uma função igualmente importante, a função de materialização [...] quando percorremos a cidade, pois os prédios falam e agem, não menos que as pessoas que neles habitam; e, graças às estruturas físicas da cidade, acontecimentos passados, decisões tomadas há muito tempo, valores formulados e alcançados, permanecem vivos e exercem uma influência.

O autor acrescenta a alternância entre a materialização e a eterização em que o significado simbólico assume formas materiais, citando Rousseau: "casas fazem uma cidade, mas cidadão fazem uma cividade" (apud, 1965, p.127). Essa dicotomia de subjetividade e matéria despontava no pensamento e na prática do ser humano, afirmando que o "planejamento da cidade é, dessa maneira, o ponto culminante de um adequado processo de materialização" (MUMFORD, 1965, p.153).

Da aldeia como uma fortificação para sua própria defesa, avançou as muralhas, ganhando mais espaço com o objetivo principal de atender as necessidades humanas. A cidade como escreve Mumford (1965, p.708),

[...] deveu sua existência, e mais ainda o seu engrandecimento, a tentativas concentradas de controlar outros homens e dominar, com força coletiva, a totalidade do ambiente. Assim, a cidade tornou-se um serviço público de captura do poder, projetado por agentes reais, que reuniam as energias dispersas de pequenas comunidades num gigantesco reservatório, regulavam coletivamente sua acumulação e fluxo e dirigiam-nos para novos canais ora favorecendo as unidades menores pela benéfica remodelação da paisagem, mas com o tempo lançando as suas energias para fora, em destruidores ataques a outra cidade. Libertação e escravidão, liberdade e compulsão, têm-se mostrados presentes desde o princípio na cultura urbana.

Carlos (2001, p.24) vai ao encontro das ideias já expostas por Mumford, salientando ainda que, 


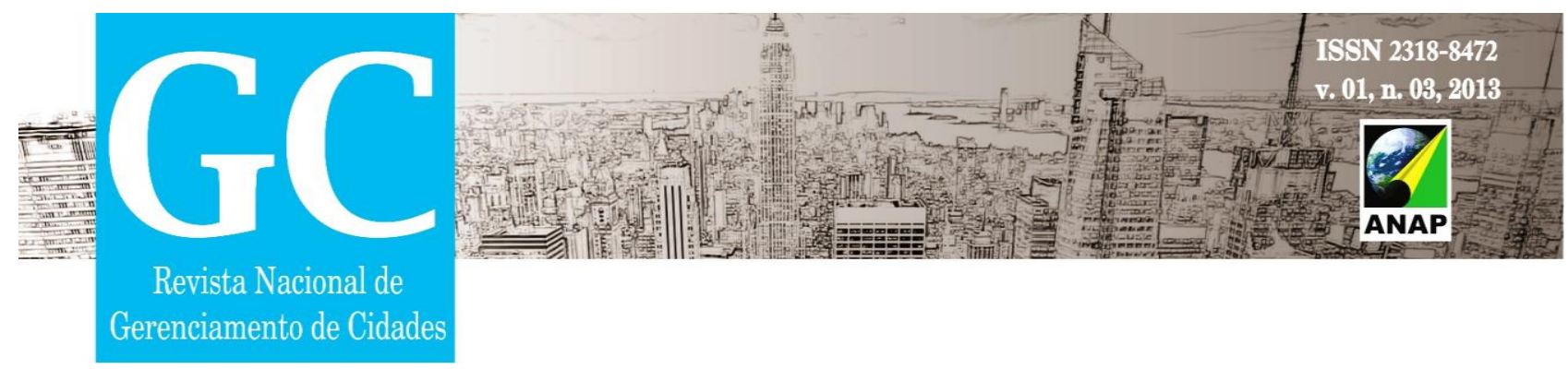

[...] a paisagem é humana, tem a dimensão da história e do socialmente reproduzido pela vida do homem. É expressão do trabalho social materializado mas também é expressão de um modo de vida. A desigualdade que pode ser percebida "no olhar-se a paisagem" é consequência dos contrastes decorrentes do processo de produção do espaço urbano. As relações criam as formas e as funções que devem ser cumpridas.

Para Abrams (1977, p.144), "um planejador deve considerar as cidades de todo mundo como organismos em processo. Suas formas, suas populações e seus usos da terra ainda não estão moldados. À proporção que a terra é comparada na órbita urbana, a forma e a organização da metrópole vão-se transformando".

Esta dinâmica acaba provocando o que Lynch (1977) aponta como falha relacionada à cidade, sendo uma delas a inelegibilidade que contribui para a alienação, o homem se torna o "estranho no ninho", estranheza que não relaciona as partes no todo perdendo o sentido da individualidade, ou melhor, sua identidade. A casa e o seu entorno, se torna à expressão de sua história, da sua personalidade, considerada "asilo inviolável" no artigo $5^{\circ}$ inciso XI da Constituição Brasileira de 1988.

Não podemos analisar a cidade apenas em sua forma, mas nos quatro itens: forma, função, processo e estrutura fazem parte de uma soma na totalidade e nas quatro funções básicas e universais do ser humano, segundo Ribeiro e Cardoso (1990): habitar, trabalhar, recrear e circular.

O espaço e a cidade não são simplesmente objetos concretos de edificações, mas a produção e reprodução que o ser humano manipula. Sobre isso Santos (1997) afirma que 'a essência do espaço é social', agindo assim, ser humano passa a atribuir um valor particular ao lugar, processo este chamado de valorização do espaço por Moraes (2005, p.35). Este valor diferencia os lugares muito mais pelas características humanas e não apenas pelas naturais. Essa intervenção na paisagem altera o ambiente, desfigurando-o tornando-se um 'elemento revelador' da sua história.

$\mathrm{Na}$ configuração deste espaço, a urbanização tornou-se espelho de desenvolvimento, considerada como 'civilizar', 'polir' ou 'embelezar' (cidade ou parte dela) no aspecto da língua portuguesa e ao nível de planejamento passa a ser sinônimo das palavras: 'renovação', 'ordenamento', 'remoção' ou 'reforma'. O país desenvolvido deveria 

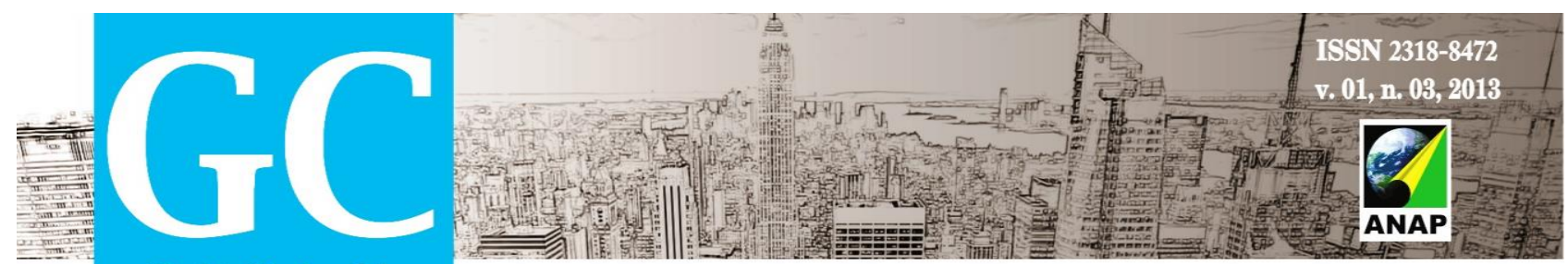

Revista Nacional de

Gerenciamento de Cidades

ser marcado pela alta industrialização, melhorias na saúde e aumento na expectativa de vida, repercutindo em seu espaço.

$\mathrm{Na}$ busca de tal melhoria, o termo explorado no mundo capitalista, 'qualidade de um produto', pode ser detectada na forma e na função deste, com as várias certificações para conferir e dar selo a esta qualidade. Porém, Leff (2000, p.149) salienta que "a análise da qualidade de vida é a percepção do sujeito de suas condições de existência". Além disso, que "a qualidade de vida está necessariamente conectada com a qualidade do ambiente e a satisfação das necessidades básicas". Assim, esses itens transitam na esfera subjetiva.

Santos (2008) conceitua urbanização corporativa a rede de agentes vinculados à expansão capitalista que são orientados para investimentos econômicos em detrimento dos sociais, exemplo que podemos observar em Conniff (2006), quando este cita a urbanização da zona Sul do Rio de Janeiro no século XIX, como um investimento com mais aplicações do que os subúrbios e reconhecido pelos agentes envolvidos por beneficiar a elite e estrangeiros.

Silva (2003, p.48) referindo-se ao arrasamento do Morro do Castelo, lembra que:

[...] as elites e as classes médias, desde o início do século, estavam tomando conta dos espaços públicos da cidade, mas isso não era novidade para os moradores pobres do Castelo, que já o haviam transformado num grande cortiço. Muito antes das elites "irem às ruas", as lavadeiras, as prostitutas e os malandros faziam da rua a sua casa.

O espaço público é um espaço social que para Souza (2007, p.99)

[...] é ao mesmo tempo, um produto das relações sociais, e um condicionador dessas mesmas relações. A organização espacial e as formas espaciais refletem o tipo de sociedade que as produziu, mas a organização espacial e as formas espaciais, uma vez produzidas, influenciam os processos sociais subsequentes.

Andrade (2006, p.110) lembra alguns aspectos físicos quanto a praças e parques; "as edificações que delimitam praças e parques têm um papel no caráter desses espaços, seja pela qualidade de suas funções, seja pelo seu aspecto simbólico". Mumford (2004, p.430) ao rever a história sobre a praça, aponta que estas inicialmente, foram construídas 


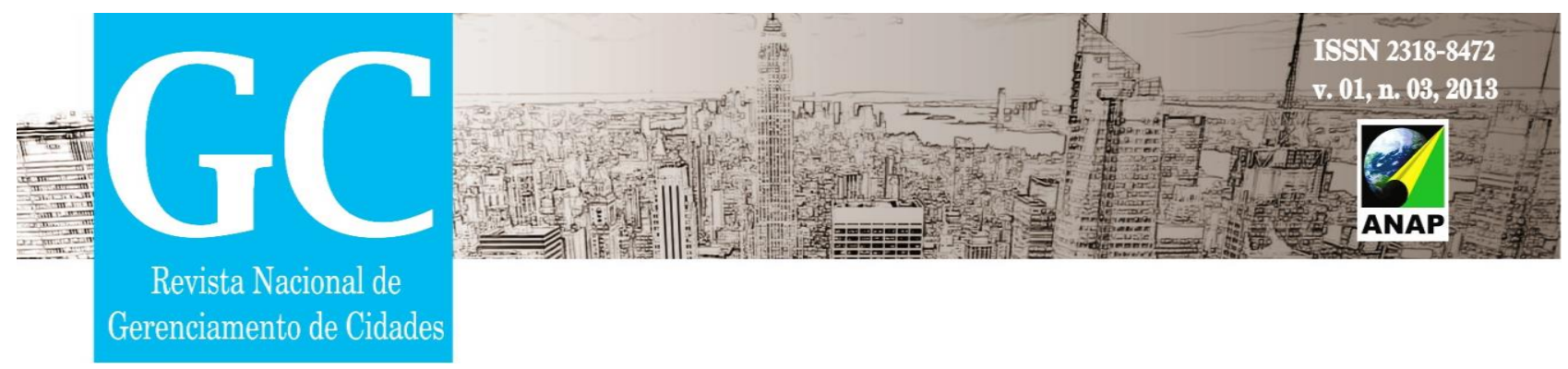

para estacionamento de veículos, transformadas através de quintais residenciais, com a redução e busca de imóvel na conversão do lucro, já no século XVIII,

[...] a transformação da praça residencial foi mais além. No traçado da maioria das praças, destinara-se espaço insuficiente para os quintais; na verdade, esses quintais não demoraram a se transformar em áreas calçadas utilitárias, onde se batiam tapetes e se penduravam roupas para secar. Quando essa falta foi suficientemente sentida, os proprietários das casas da praça transformaram o espaço aberto vazio num jardim ou parque comum.

Após três séculos, a praça passa a ser espaço para lazer, o quintal cada vez mais reduzido, hoje temos o "play", a laje e a praça de alimentação no shopping. Outro dado que podemos observar, está na arborização que, de acordo com urbanistas como Farah (2006, p.167), "as árvores podem suscitar forte identidade à paisagem, tornando o ambiente mais acolhedor, facilmente identificável, contribuindo para uma paisagem afetiva". Costa (2003) cita o conceito de Derani quanto ao meio ambiente considerando um "conjunto de condições de existência humana que integra e influencia o relacionamento entre os homens, sua saúde e o seu desenvolvimento" a autora relaciona este conceito a qualidade de vida.

Neste sentido, Leff $(2006$, p.148) salienta que "a qualidade de vida, pelos elementos que a definem, não permitem generalizar as necessidades sociais, nem sequer por estratos ou grupos sociais. A qualidade de vida é um processo no qual diversas circunstâncias incidem em um indivíduo", repercutindo em sua saúde.

Face a isto, o ambiente faz parte da 'higiene mental' e esta, passa a ser um ramo da saúde pública onde, Begler(1984) aponta na constelação multifatorial que envolve a 'psicohigiene' que "têm sua esfera de atuação no seio da comunidade, sobre todos os aspectos das condições de vida e do tipo de vida que desenvolve na comunidade". Por outro lado, é importante mencionar que em 2009, 450 milhões de pessoas foram diagnosticadas com depressão e segundo a expectativa da OMS (Organização Mundial de Saúde), em 2030, será a maior causa de perdas (para a população) entre todos os problemas de saúde, acarretando altos custos em seu tratamento para o governo de um país. Shekhar Saxena, médico do Departamento de Saúde Mental da OMS, enfatiza que "a depressão tem diversas causas, algumas delas biológicas, mas parte dessas causas 


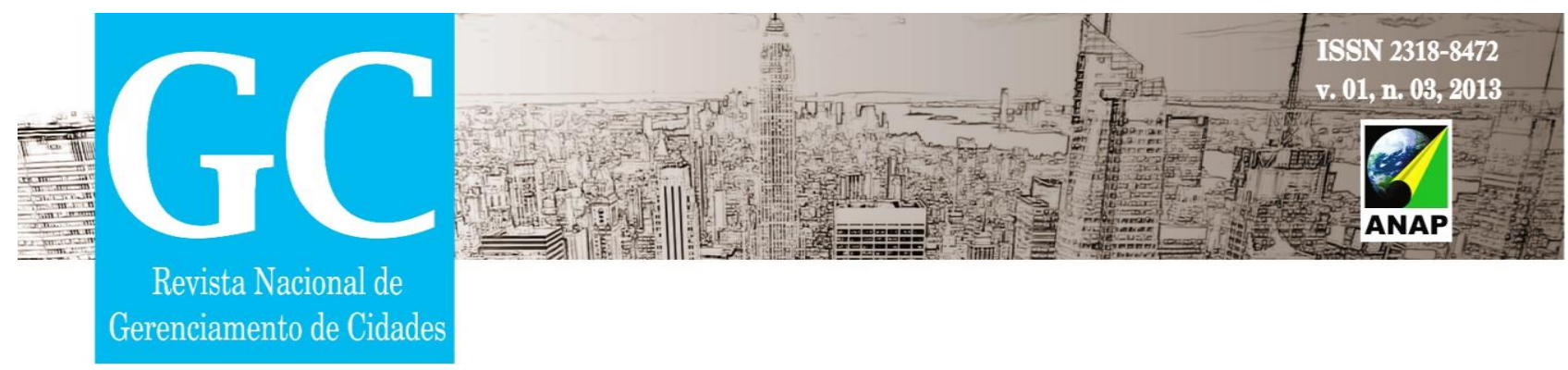

vem de pressões ambientais e, obviamente, as pessoas pobres sofrem mais estresse em seu dia-a-dia do que as pessoas ricas, e não é surpreendente que elas tenham mais depressão".

Santos (2007) observa o ciclo entre a especulação imobiliária e o déficit de residências conduzindo a 'periferização da população mais pobre' onde a 'cidade econômica' se sobrepõe a 'cidade social', não incluindo na lógica do mercado o 'espaço do cidadão', espaço este também para a promoção de sua saúde mental.

Para Leff (2006, p. 149) a qualidade de vida depende da "percepção do sujeito de suas condições de existência", a relação social gera essa subjetividade, suas necessidades básicas não se delimitam nas questões fisiológicas de sobrevivência, as psicológicas são imperantes nos motivos que levam ao comportamento e a interagir com o seu ambiente. Assim, o conceito de qualidade de vida, parte de abstrações, nem sempre mensuráveis e variando de cultura e grupos, com a interferência das representações sociais destes. Como exemplifica Leff (2006, p.149), "a percepção das 'condições de existência' gera processos de adaptação a situações impostas ou de mobilização social de protesto, incorporando em suas lutas demandas por novas formas de satisfação de necessidades além das normas estabelecidas pelos benefícios da economia de mercado e do planejamento nacional".

Neste ponto, Leff (2006, p.149) estabelece dois tipos de grupo, de um lado o conformismo através de adaptações e outro em busca de novas formas de satisfações. Essa divisão será caracterizada segundo a percepção de cada ser humano de suas "condições de existência". A percepção passa a ter uma função mediadora com o mundo social. O ambiente é interpretado não em termos de objetos, mas o que ele representa para a história do grupo social, podendo com isso ser ponto de partida de mudanças ou manutenção de uma ordem reacionária.

Como salienta Chalhoub (1996, p.58): "O mais trágico em toda essa história é que a alegação de 'cientificidade', de 'neutralidade' nas decisões administrativas, traz sempre em seu cerne a violência contra a cidadania". Com efeito, vale lembrar as reformas urbanas inspiradas na de Paris, do século XIX, o 'modelo higienista', o 'modelo sanitário 

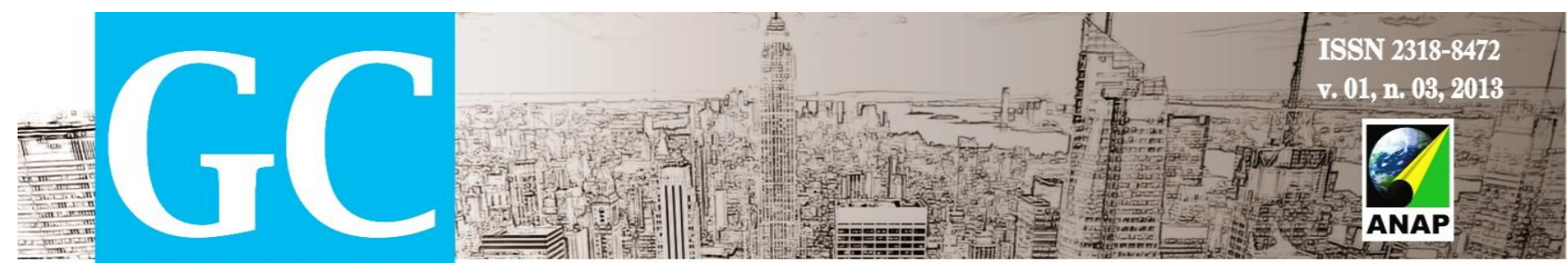

Revista Nacional de

Gerenciamento de Cidades

inglês', entre outros. Glazer (1977) lembra que os planejadores urbanos se baseiam no custo e benefício, não levando em conta a totalidade desencadeada no processo social e suas consequências na vida do cidadão.

\section{CONCLUSÃO}

O espaço vivido é um espaço de produção e reprodução contido em meio às lutas. Conhecer e incorporar informações de um grupo gera um processo de reprodução ou de mudanças com suas limitações e delimitações, assim, o território pode transformarse em um 'gueto' de um grupo onde a casa torna-se sua 'prisão'.

O 'saber científico e ordenador do espaço urbano' coloca-se acima da voz do cidadão. Nesse cenário, o habitante da cidade passa a ser um estranho no seu ambiente, emaranhado em paradigmas: do 'desenvolvimento', da 'reforma', do 'ordenamento' entre outros, que adquirem características míticas.

O conhecimento científico de um lado incrementou a industrialização, mas, como sabemos, não garantiu a qualidade de vida, repercutindo "entre outros fatores, na destruição e na poluição do ambiente, distorções de urbanização e alienação do ser humano" (OLIVEIRA, 2006, p.26).

Reconhecer o direito à qualidade de vida transforma-se, portanto, em uma questão de direito à saúde pública. Implica não apenas na existência de legislações, mas na 'sensibilização do coletivo' e a construir novos saberes vinculados às questões sociais, na busca de um diálogo em que a voz do cidadão possibilitará a reflexão e o questionamento de como planejar o espaço urbano. Assim, a história de lutas e desafios devem ser encarados como possibilidades de se repensar um planejamento, não sendo a intervenção somente de um especialista como aponta Silva (2003). Os desafios estão no 'campo do poder' onde, o cidadão historicamente continua sua luta para ser visto como parte integrante do locus urbano participativo. 


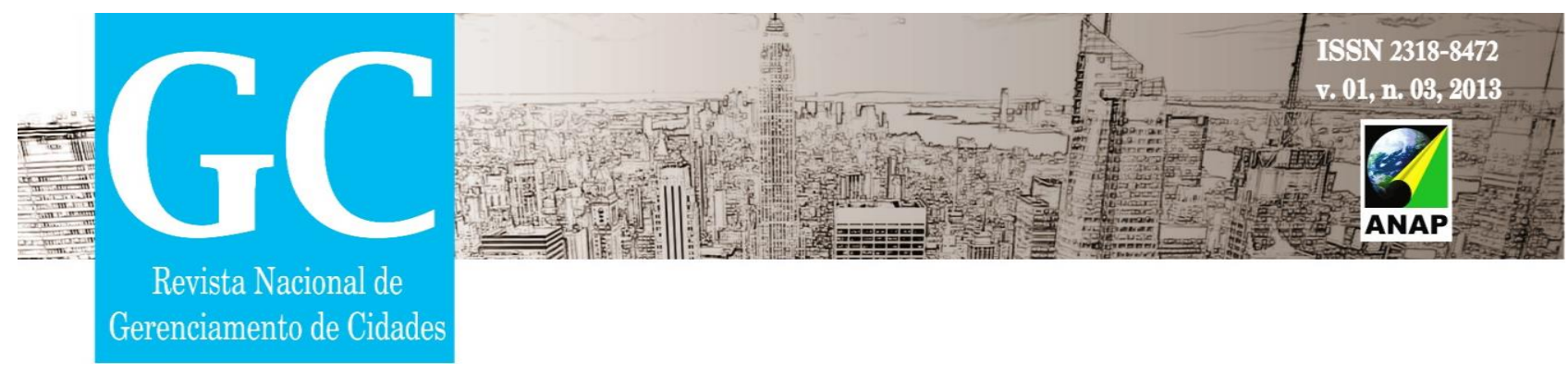

\section{REFERÊNCIAS}

ANDRADE, L. da S. Qual futuro esperar para as favelas? Um debate sobre a qualidade dos espaços físicos de assentamentos populares à luz de conceitos de espaço público. In: Machado, D.B.P. (orgs). Sobre o Urbanismo. Rio de Janeiro: PROURB, 2006.

BLEGER, J Psico-Higiene e psicologia Institucional - Porto Alegre: Artmed. 1984

BRASIL. Lei Orgânica da Saúde. Lei oㅡ 8080 de 19 de setembro de 1990.

CARLOS, A F A A cidade . São Paulo:Contexto. 2001

CHALHOUB, S. Cidade febril. Cortiços e epidemias na Corte imperial, Rio de Janeiro:Companhia das Letras.1996.

CONNIFF, M L . Política a no Brasil - A ascensão do populismo 1925 -1945. Rio de Janeiro:Relume Dumará. 2006

CORREA, R. L. Espaço urbano. Séries princípios. São Paulo:Ática, 1989

Região e organização espacial. 8ª ed., São Paulo: Ática. 2007

DAVIS, K; GLAZER, N; SJOBERG, G. et alli. Cidades. A urbanização da humanidade. $3^{\underline{a}}$ ed. Rio de Janeiro: Zahar. 1977

COSTA, E A - Vigilância Sanitária: proteção e Defesa da Saúde: In Epidemiologia e saúde. Rouquayrol, M Z; Almeida Filho, N de. 6ª ed.Rio de Janeiro: Medsi. 2003

DEMIER, F. A lei do desenvolvimento desigual e combinado de Leon Trotsky e a intelectualidade brasileira: breves comentários sobre uma relação pouco conhecida. Disponível em:<

http://www.unicamp.br/cemarx/anais_v_coloquio_arquivos/arquivos/cominicacoes/gt3/ses sao3/Felipe_Demier.pdf $>$. Acesso em 08 nov 2008.

FARAH, I M C . Rio de Janeiro e árvores urbanas: uma paisagem afetiva: Sobre Urbanismo, Machado, D B P (org). Rio de Janeiro:PROURB. 2006

LEFF, E. Epistemologia ambiental .4를 ed, São Paulo:Cortez.2006 

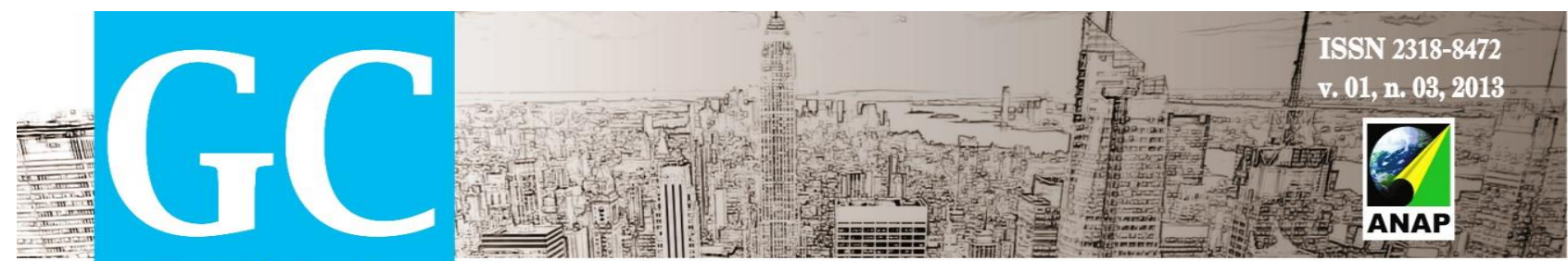

Revista Nacional de

Gerenciamento de Cidades

Racionalidade ambiental, a reapropriação social da natureza. Rio de Janeiro:Civilização Brasileira. 2000. Disponível em:< http://www.lite.fae.unicamp.br/papet/2003/ep145/pesq.htm >. Acesso em 30 jul. 2008

MORAES, A C . Geografia. Pequena história critica. $20^{\underline{a}}$ ed. São Paulo:Annablume. 2005

MUMFORD, L. A cidade na história - Vol. I e II Belo Horizonte:Itatiaia. 1965;

OLIVEIRA, G B; SOUZA_LIMA, J E de (orgs). O desenvolvimento sustentável em foco. Uma contribuição multidisciplinar. São Paulo: Annablume. 2006.

A cidade na história. Suas origens, transformações e perspectivas. São Paulo:Martins Fontes. 2004

RIBEIRO, L. C. de Q., CARDOSO, A. L. Plano diretor e gestão democrática da cidade. Revista de Administração Municipal, Rio de Janeiro, v.27, n.196, p.8-20, jul./set. 1990

SANTOS, M Espaço e método - $4^{\text {a }}$ ed. São Paulo:Nobel. 1997 O espaço do cidadão - $7^{\text {a }}$ ed. São Paulo:EDUSP. 2007 A urbanização Brasileira - 5aㅗ ed. São Paulo:EDUSP. 2008

SILVA, L. H. P. História do urbanismo no Rio de Janeiro. Rio de Janeiro:E-papers. 2003

SOUZA, M. J. L. ABC do desenvolvimento urbano. $3^{\text {a }}$ ed. Rio de Janeiro: Bertrand Brasil. 2007 